\title{
Effectiveness and Adverse Effects of Tranexamic Acid in Bleeding during Adenotonsillectomy: A Randomized, Controlled, Double-blind Clinical Trial
}

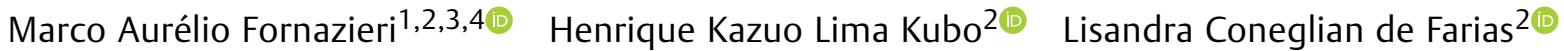 \\ Adriano Morita Fernandes da Silva ${ }^{1,2}$ Ellen Cristine Duarte Garcia1® \\ Gustavo de Alcântara Lopes dos Santos ${ }^{4}$ Fábio de Rezende Pinna ${ }^{3(0)}$ Richard Louis Voegels ${ }^{3}$ (i)
}

${ }^{1}$ Department of Surgery, Universidade Estadual de Londrina, Londrina, PR, Brazil

2 Department of Medicine, Pontifícia Universidade Católica do Paraná, Londrina, PR, Brazil

${ }^{3}$ Department of Otorhinolaryngology, Universidade de São Paulo, São Paulo, SP, Brazil

4 Centro Londrinense de Otorrinolaringologia, Londrina, PR, Brazil
Address for correspondence Marco Aurélio Fornazieri, MD, PhD, Department of Clinical Surgery, Londrina State University, 60 Robert Koch Avenue, Londrina PR, 86038350, Brazil

(e-mail: marcofornazieri@uel.br).

\begin{abstract}
Keywords

- tranexamic acid

- adenoidectomy

- tonsillectomy

- adenotonsillectomy

Introduction Intra and postoperative bleeding are the most frequent and feared complications in adenotonsillectomy (AT). Tranexamic acid (TXA), which is known for its antifibrinolytic effects, has a proven benefit in reducing bleeding in hemorrhagic trauma and cardiac surgery; however, the effectiveness and timing of its application in AT have not yet been established.

Objectives We aimed to evaluate the efficacy of TXA in controlling bleeding during and after AT and assess its possible adverse effects in children.

Methods The present randomized, controlled, double-blind clinical trial included 63 children aged 2 to 12 years. They were randomly assigned to receive either intravenous TXA $(10 \mathrm{mg} / \mathrm{kg})$ or placebo 10 minutes before surgery. The volume of intraoperative bleeding, presence of postoperative bleeding, and adverse effects during and 8 hours after the surgery were assessed.

Results No difference in bleeding volume was noted between the 2 groups (mean, $122.7 \mathrm{ml}$ in the TXA group versus $115.5 \mathrm{ml}$ in the placebo group, $p=0.36$ ). No intraoperative or postoperative adverse effects were noted because of TXA use. Furthermore, no primary or secondary postoperative bleeding was observed in any of the participants.

Conclusion In our pediatric sample, TXA $(10 \mathrm{mg} / \mathrm{kg})$ administration before AT was safely used, without any adverse effects. It did not reduce the bleeding volume in children during this type of surgery. Future studies should assess the use of higher doses of TXA and its administration at other time points before or during surgery.
\end{abstract}

received

August 7, 2020

accepted

November 16, 2020

published online

February 19, 2021
DOI https://doi.org/

10.1055/s-0040-1722255. ISSN 1809-9777.

\footnotetext{
(C) 2021. Fundação Otorrinolaringologia. All rights reserved.

This is an open access article published by Thieme under the terms of the Creative Commons Attribution-NonDerivative-NonCommercial-License, permitting copying and reproduction so long as the original work is given appropriate credit. Contents may not be used for commercial purposes, or adapted, remixed, transformed or built upon. (https://creativecommons.org/ licenses/by-nc-nd/4.0/)

Thieme Revinter Publicações Ltda., Rua do Matoso 170, Rio de Janeiro, RJ, CEP 20270-135, Brazil
} 


\section{Introduction}

The common complications of adenotonsillectomies (ATs) in children are severe postoperative pain, otalgia, local infection, severe nausea, prolonged dysphagia, velopharyngeal insufficiency, anxiety, adverse effects of anesthesia, and especially, bleeding during and after surgery. ${ }^{1-6}$

When vascular structures are injured during surgical procedures, they trigger a rapid, localized, and complexly regulated hemostatic response. The hemostatic process involves four phases: a) endothelial aggression and platelet plug formation; b) activation of the coagulation cascade; c) antithrombotic control mechanisms; and d) clot removal by fibrinolysis. ${ }^{7,8}$ Therefore, medications that inhibit fibrinolysis have the potential to reduce bleeding after surgery. Tranexamic acid (TXA) is one of the most studied antifibrinolytic medication. Tranexamic acid has good tolerability and low cost; it is a synthetic derivative of the amino acid lysine; and can displace fibrin plasminogen and inhibit plasmin proteolytic activity, thereby inhibiting fibrinolysis. ${ }^{9,10}$

The hemostatic efficacy of TXA has been proven in orthopedic, cardiac, obstetric, and otorhinolaryngological surgeries. ${ }^{11-15}$ A study revealed that the overall and bleeding-related mortality of hemorrhagic trauma patients considerably reduced after they received an attack dose of $1 \mathrm{~g}$ of TXA intravenously followed by an infusion of $1 \mathrm{~g}$ of TXA over 8 hours. ${ }^{16}$ In addition, a recent meta-analysis involving more than 10,000 patients revealed that TXA reduces transfusion requirements by approximately one-third. ${ }^{17}$ The most commonly reported side effects of TXA are nausea and diarrhea. ${ }^{18}$

Until now, only a few clinical trials have evaluated decreased intra and postoperative bleeding volumes in children who received TXA during ATs. While some studies demonstrated no difference, ${ }^{19,20}$ others revealed a lower bleeding volume when
TXA was used. ${ }^{21}$ Considering the need for further evidence regarding the potential beneficial effects of TXA in ATs of pediatric patients, we aimed to verify the efficacy and safety of TXA.

\section{Methods}

\section{Participants}

In the present study, 63 children aged 2 to 12 years old were recruited from September 2017 to May 2018. The children were treated at the otorhinolaryngology clinic of the $\mathrm{XX}$ hospital and had an indication for adenotonsillectomy owing to recurrent infections or adenotonsillar hypertrophy. All were submitted to a questionnaire for assessment of bleeding risk by von Willebrand type 1 disease (-Table 1 ), excluding those with definite suspicion of having this condition. ${ }^{22}$ Children who underwent surgery in the 2 months prior to the study; those with a history of infection in the month prior to the study, altered coagulogram, other coagulation disorders, and increased risks of anesthetic intervention; and those who used medications that could interfere with blood coagulation were excluded. The total surgical time (minutes) was calculated, beginning when the surgeon initiated the procedure until the surgeon informed the anesthesiologist about its conclusion.

This study was conducted after obtaining approval from the local research ethics committee (2.169.256). Parents or legal guardians of the children signed the informed consent form after they were provided with a detailed explanation about the purpose of the study.

\section{Randomization, Interventions, and Blinding}

The patients included in the present study were categorized into two groups: placebo (A) and TXA (B) groups. Randomization was performed using permuted blocks, and to blind

Table 1 Questionnaire for assessing hemorrhagic symptoms in suspected Von Willebrand type 1 patients

\begin{tabular}{|l|}
\hline Significant bleeding symptoms: \\
\hline 1 ( ) $\geq 2$ episodes of epistaxis, no history of trauma and without compression improvement of up to 10 minute or $\geq 1$ \\
episode requiring red blood cell transfusion
\end{tabular}


participant allocation, identical, opaque, sealed envelopes containing the letters A and B were used. A nurse opened each envelope, identified which group the patient was assigned to, and intravenously administered either TXA (Hospital Norte Paranaense, Transamin $10 \mathrm{mg} / \mathrm{kg}$ bolus) or placebo (same amount of saline) before anesthetic induction (10 minute before initiating the surgical procedure) using a transparent syringe. The dosage was the recommended by the pharmaceutical company for the pediatric population. The surgeon and staff participating in the surgery had no further involvement in the progress of the study. Researchers, patients, postoperative care team, and outcome scale evaluators were unaware of the groups to which each patient belonged.

\section{Surgical Technique}

Adenotonsillectomy surgery was performed in the standardized way by a single surgeon (G.A.L.S.). The surgeon used only cold instruments, mainly the tonsil dissector, without closing the tonsillar fossa or cauterization. First, a palatoglossal arch incision was made, and the palatine tonsil was subsequently detached using a proper tonsil dissector aspirator. Sutures were done inside the musculature for bleeding control when necessary, however, never closing the fossa. The adenoidectomy was performed by a curette. Regarding anesthetic induction, all patients received the medications commonly used for anesthetic induction and inhalational maintenance. The patients also received the same medications as part of the usual surgical procedure, which was noted in the patient study form.

\section{Bleeding Volume and Assessment of Adverse Effects}

The primary endpoint of this study was the volume of blood loss $(\mathrm{ml})$, which was measured using a collector after completing the surgery. Other outcomes were primary and secondary postoperative bleeding, occurring until 24 hours and more than 24 hours after surgery, respectively. Adverse effects, such as skin reactions, nausea, vomiting, headache, diarrhea, seizure, and dizziness, were evaluated during and 8 hours after the surgery. The severity of the possible adverse effects was assessed using the Common Terminology Criteria for Adverse Events scale. ${ }^{23}$

\section{Statistical Analysis}

It was calculated that 23 individuals were needed for each group to detect a clinically significant difference in bleeding volume loss of $50 \mathrm{ml}$ with a $5 \%$ $\alpha$ level, $90 \%$ power, and a standard deviation of $50 \mathrm{ml}^{24}$ To increase the power of the study, we increased our sample to a minimum of 31 individuals per group. Data of continuous variables are presented as mean and standard deviation. Categorical variables are described as percentage and their respective $95 \%$ confidence intervals. After verifying the absence

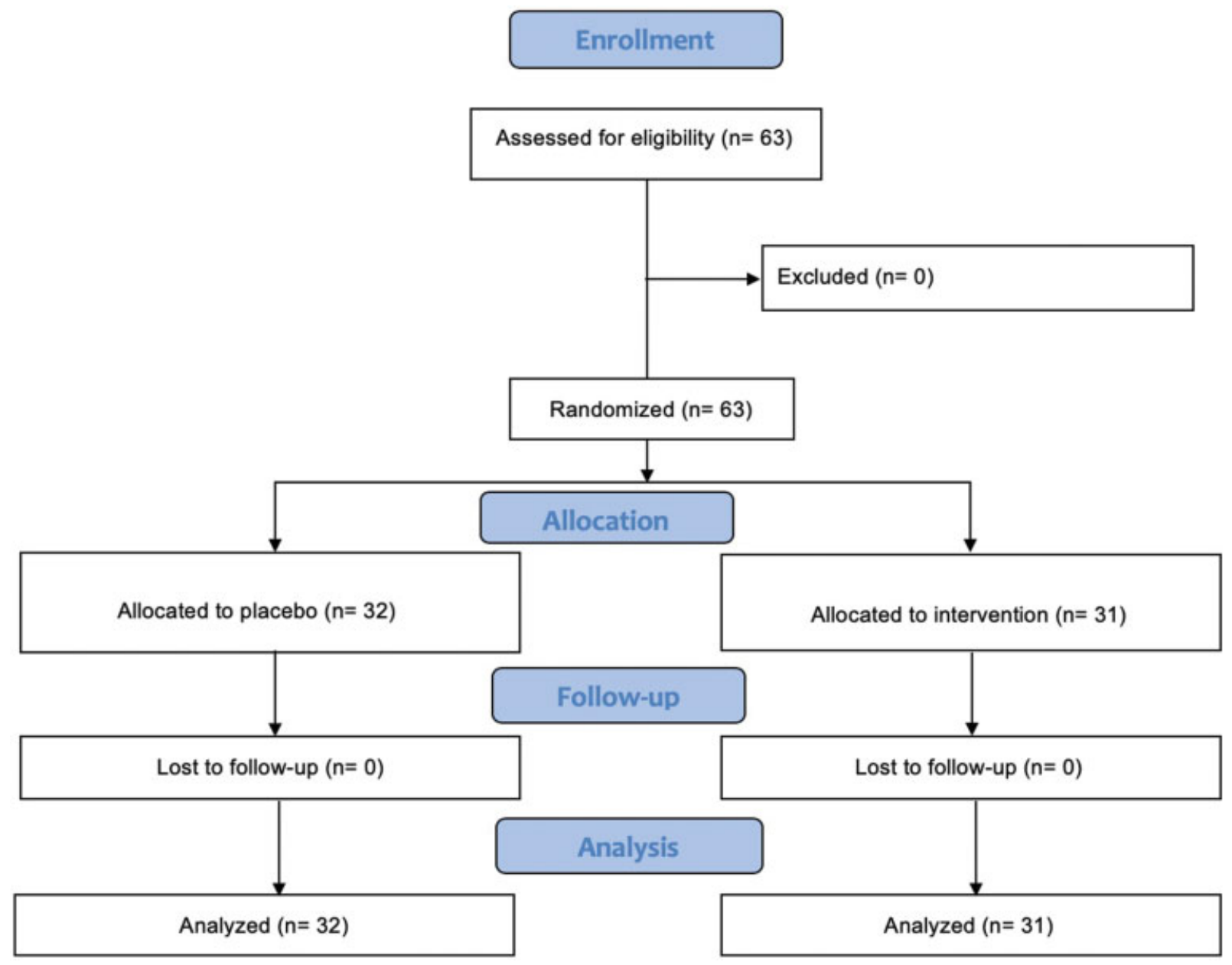

Fig. 1 Flow diagram of the children enrolled. 
Table 2 Clinical data of patients in the placebo and tranexamic acid groups

\begin{tabular}{|l|l|l|}
\hline Variable & $\begin{array}{l}\text { Placebo } \\
\mathbf{n}(32)\end{array}$ & $\begin{array}{l}\text { TXA } \\
\mathbf{n}(31)\end{array}$ \\
\hline Age (mean, SD) (years) & $5.5(2.5)$ & $6.4(2.5)$ \\
\hline Sex (\% male) & 62.5 & 54.8 \\
\hline Weight (mean, SD) (kg) & $25(15.4)$ & $27.1(11.2)$ \\
\hline Surgical indication & & \\
\hline Hypertrophy (\%) & 84.4 & 87.1 \\
\hline Chronic tonsilitis (\%) & 15.6 & 12.9 \\
\hline
\end{tabular}

Abbreviations: SD, standard deviation; TXA, tranexamic acid.

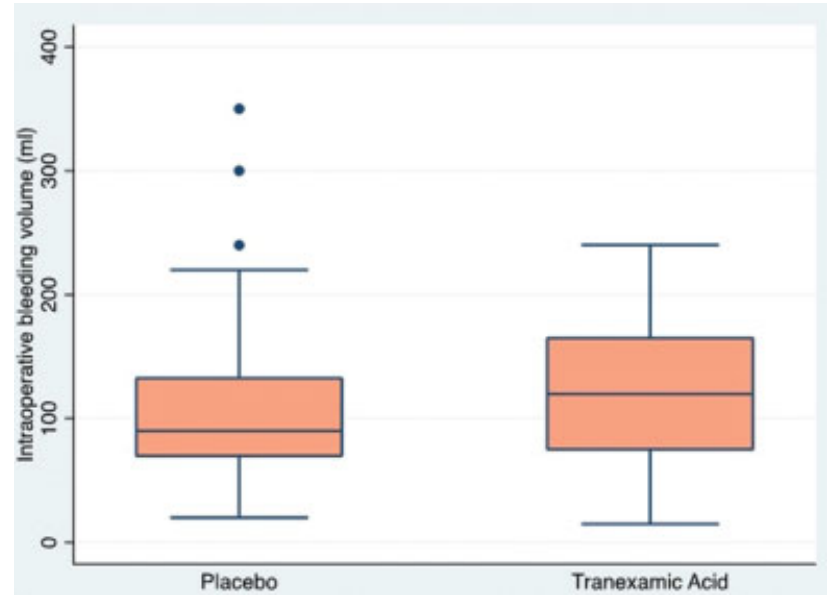

Fig. 2 Bleeding volume during surgery among children using the placebo or tranexamic acid.

of normality for at least one of the continuous variables' distributions using the Shapiro-Wilk test, the surgery time and bleeding volume were compared using the Mann-Whitney test. Correlation analyses among age, weight, and volume were performed using Spearman correlation coefficient.

\section{Results}

In total, 63 children were randomly assigned to two groups: 31 children received TXA and 32 received the placebo (-Fig. $\mathbf{1}$ ). The clinical characteristics of the patients are described in -Table 2. There was no significant difference between the two groups with respect to gender, weight, and age.

The blood volume lost during the surgical procedure was analogous between the placebo and ATX groups (mean [SD, $95 \% \mathrm{CI}]$ placebo $=115.5 \mathrm{ml}[73.1,89.2-141.9]$ versus TXA $=122.7 \mathrm{ml}[59.5,100.9-144.6], p=0.36$; - Fig. 2). The use of TXA did not decrease surgical time (mean [SD] placebo $=16.4$ [7.1] $\mathrm{min}$ versus TXA $=16$ [4.2] $\mathrm{min}, p=0.25$ ).

In children, it is estimated that the total blood volume is 75 to $80 \mathrm{ml} / \mathrm{kg} .^{25}$ Considering this value, the group using TXA lost 6.1\% (CI 95\%: 4.9-7.3), and the controls lost 6.2\% (CI 95\%: 5.1-7.4) during the procedure.

Furthermore, as expected, the bleeding volume correlated with the age $(r=0.48, p<0.001)$ and weight $(r=0.50$, $p<0.001$; - Fig. 3 ) of the children. The surgical time also correlated with weight $(r=0.28, p=0.03)$ but not with age $(r=0.23, p=0.07)$. Finally, none of the children had primary or secondary postoperative bleeding or any of the adverse effects evaluated.
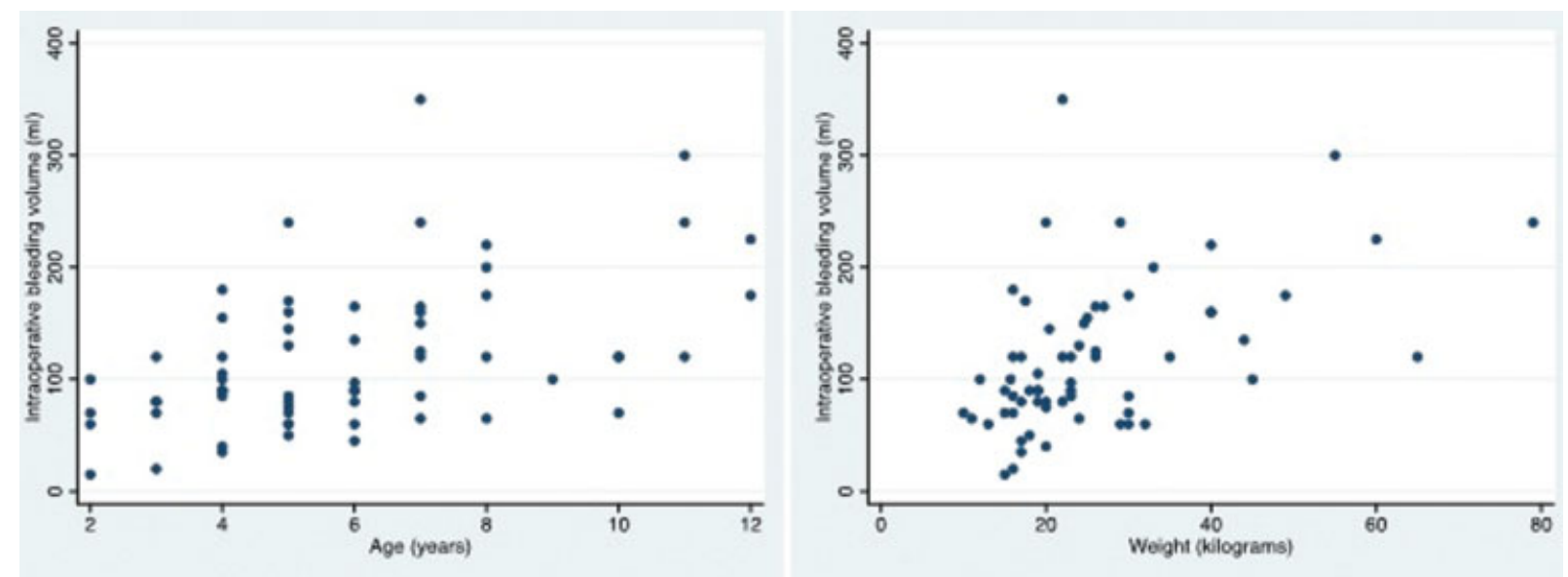

Fig. 3 Scatter plots showing a moderate correlation between perioperative bleeding volume and age and weight of children. 


\section{Discussion}

Although TXA is inexpensive, well-tolerated, and widely used in various surgical procedures to contain blood loss, its usefulness when administered to children undergoing ATs has not been established. In our study, none of the patients had side effects, thereby providing evidence regarding the safety of TXA in this pediatric population. In addition, we addressed important sources of biases in such surgical clinical trials. Specifically, a single surgeon performed the surgeries, and all procedures were performed in one hospital only with the aid of the same anesthetic team using similar medications and dosages throughout the data collection period.

Brum et al. (2012) reported similar results in their study of 95 children aged 4 to 12 years, of both sexes, who underwent AT. These children received intravenous TXA $(10 \mathrm{mg} / \mathrm{kg})$ preoperatively and 8 to 16 hours postoperatively. No statistically significant reduction in intraoperative bleeding volume was observed with TXA use (mean [SD] placebo $=158.21 \mathrm{ml}$ [88.1] versus $\mathrm{TXA}=135.1 \mathrm{ml}$ [71.4], $p=0.19) .{ }^{19}$ Furthermore, they did not observe any difference regarding postoperative bleeding during AT. Therefore, TXA did not appear to be effective in reducing bleeding in children. Moreover, a recent Japanese study of 117,598 patients who underwent tonsillectomy revealed that TXA use on the day of surgery did not reduce the rate of reoperation and blood transfusion. ${ }^{26}$

Considering the percentage of blood loss to the total blood volume during the adenotonsillectomy of $\sim 6 \%$ in our sample, our results are similar to previous studies ${ }^{27}$ and a little higher than others. ${ }^{28}$ It is important to highlight that the surgeon who performed the procedures avoids cauterization, because of worse postoperative pain related to this technique, and prefers sutures to contain the bleeding, potentially leading to a higher blood loss.

In the current study, we found a moderately positive correlation between bleeding volume and age and weight. Older and heavier children had higher blood loss, which was probably related to the longer time required to perform the surgery and also owing to the higher number of previous infections of the palatine tonsils, which made their detachment more difficult.

It is noteworthy that none of the patients who received TXA presented any adverse effects, neither during the surgery nor postoperatively. Thus, the $10-\mathrm{mg} / \mathrm{kg}$ TXA dose appears to be safe in children.

The present study had some limitations. Our sample population was small for the complete evaluation of possible adverse effects of TXA. In addition, we evaluated only one route of administration, a single dose, and just one time point of preoperative administration. Considering that after the oral administration of 10 to $15 \mathrm{mg} / \mathrm{kg}$ TXA, the peak plasma concentration will occur within 3 hours, further studies on the efficacy of TXA during ATs need to be performed at different doses, by different administration modes, and at different time points preoperatively.

\section{Conclusion}

The use of $10-\mathrm{mg} / \mathrm{kg}$ of TXA preoperatively was safe and had no adverse effects. However, TXA did not decrease the volume of blood loss during ATs in children. Future studies with different doses and dosing regimens are needed to elucidate the possible benefits of TXA during ATs.

Trial Registration ReBEC

U1111-1259-3915

Conflict of Interests

The authors have no conflict of interests to be declared

\section{References}

1 Schmidt R, Herzog A, Cook S, O'Reilly R, Deutsch E, Reilly J. Complications of tonsillectomy: a comparison of techniques. Arch Otolaryngol Head Neck Surg 2007;133(09):925-928. Doi: 10.1001/archotol.133.9.925

2 Collison PJ, Mettler B. Factors associated with post-tonsillectomy hemorrhage. Ear Nose Throat J 2000;79(08):640-642,644,646 passim

3 Kain ZN, Mayes LC, Caldwell-Andrews AA, Karas DE, McClain BC. Preoperative anxiety, postoperative pain, and behavioral recovery in young children undergoing surgery. Pediatrics 2006;118(02): 651-658. Doi: 10.1542/peds.2005-2920

4 Witzel MA, Rich RH, Margar-Bacal F, Cox C. Velopharyngeal insufficiency after adenoidectomy: an 8-year review. Int J Pediatr Otorhinolaryngol 1986;11(01):15-20. Doi: 10.1016/s0165-5876(86)80023-4

5 Eid NS, Jones VF. Bacterial tracheitis as a complication of tonsillectomy and adenoidectomy. J Pediatr 1994;125(03):401-402. Doi: 10.1016/s0022-3476(05)83284-6

6 Burton MJ, Isaacson G, Rosenfeld RM. Extracts from The Cochrane Library: Tonsillectomy for chronic/recurrent acute tonsillitis. Otolaryngol Head Neck Surg 2009;140(01):15-18

7 Furie B, Furie BC. Mechanisms of thrombus formation. N Engl J Med 2008;359(09):938-949. Doi: 10.1056/NEJMra0801082

8 Leung LLK. Overview of hemostasis [Internet]. [cited 2019 Sep 20) . Available from: http://www.uptodate.com/home/store.do

9 Levy JH, Koster A, Quinones QJ, Milling TJ, Key NS. Antifibrinolytic Therapy and Perioperative Considerations. Anesthesiology 2018; 128(03):657-670. Doi: 10.1097/ALN.0000000000001997

10 Dunn CJ, Goa KL. Tranexamic acid: a review of its use in surgery and other indications. Drugs 1999;57(06):1005-1032. Doi: 10.2165/00003495-199957060-00017

11 Sethna NF, Zurakowski D, Brustowicz RM, Bacsik J, Sullivan LJ, Shapiro F. Tranexamic acid reduces intraoperative blood loss in pediatric patients undergoing scoliosis surgery. Anesthesiology 2005;102(04):727-732. Doi: 10.1097/00000542-200504000-00006

12 Yaniv E, Shvero J, Hadar T. Hemostatic effect of tranexamic acid in elective nasal surgery. Am J Rhinol 2006;20(02):227-229

13 Sekhavat L, Tabatabaii A, Dalili M, Farajkhoda T, Tafti AD. Efficacy of tranexamic acid in reducing blood loss after cesarean section. J Matern Fetal Neonatal Med 2009;22(01):72-75. Doi: $10.1080 / 14767050802353580$

14 Myles PS, Smith JA, Forbes A, et al;ATACAS Investigators of the ANZCA Clinical Trials Network. Tranexamic Acid in Patients Undergoing Coronary-Artery Surgery. N Engl J Med 2017;376 (02):136-148. Doi: 10.1056/NEJMoa1606424

15 Wei M, Jian K, Guo Z, et al. Tranexamic acid reduces postoperative bleeding in off-pump coronary artery bypass grafting. Scand Cardiovasc J 2006;40(02):105-109. Doi: 10.1080/14017430500519864

16 Binz S, McCollester J, Thomas S, et al. CRASH-2 Study of Tranexamic Acid to Treat Bleeding in Trauma Patients: A Controversy 
Fueled by Science and Social Media. J Blood Transfus 2015; 2015:874920. Doi: 10.1155/2015/874920

17 Ker K, Edwards P, Perel P, Shakur H, Roberts I. Effect of tranexamic acid on surgical bleeding: systematic review and cumulative meta-analysis. BMJ 2012;344:e3054. Doi: 10.1136/ bmj.e3054

18 Robb PJ. Tranexamic acid - a useful drug in ENT surgery? J Laryngol Otol 2014;128(07):574-579. Doi: 10.1017/S0022215114001285

19 Brum MR, Miura MS, Castro SF, Machado GM, Lima LH, Lubianca Neto JF. Tranexamic acid in adenotonsillectomy in children: a double-blind randomized clinical trial. Int J Pediatr Otorhinolaryngol 2012;76(10):1401-1405. Doi: 10.1016/j.ijporl.2012.04.028

20 Soliman R, Alshehri A. Assessment of the effect of tranexamic acid on perioperative bleeding in pediatric patients undergoing tonsillectomy. Egypt J Anaesth 2015;31:297-301

21 Elzayat SD, Elgebaly AS. The role of tranexamic acid in improving quality of pediatric tonsillectomy: a double-blinded randomized controlled study. Menoufia Med J 2018;31:98-101

22 Sadler JE, Rodeghiero FISTH SSC Subcommittee on von Willebrand Factor. Provisional criteria for the diagnosis of VWD type 1. J Thromb Haemost 2005;3(04):775-777. Doi: 10.1111/j.15387836.2005.01245.x
23 Common Terminology Criteria for Adverse Events [Internet]. v4.0 [cited 2016 Oct 18]. . Available from: https://www.eortc.be/services/doc/ctc/ CTCAE_4.03_20100614_QuickReference_5x27.pdf

24 Castelli G, Vogt E. Der Erfolg einer antifibrinolytischen Behandlung mit Tranexamsäure zur Reduktion des Blutverlustes während und nach Tonsillektomien. [Result of an antifibrinolytic treatment using tranexamic acid for the reduction of blood-loss during and after tonsillectomy]Schweiz Med Wochenschr 1977;107(22):780-784

25 Pearson H. Blood and blood forming tissues. In: Rudolph C, Rudolph A, editors. Rudolph's pediatrics. 21st ed. New York: McGraw-Hill; 2003:1521

26 Koizumi M, Ishimaru M, Matsui H, Fushimi K, Yamasoba T, Yasunaga $\mathrm{H}$. Tranexamic acid and post-tonsillectomy hemorrhage: propensity score and instrumental variable analyses. Eur Arch Otorhinolaryngol 2019;276(01):249-254. Doi: 10.1007/ s00405-018-5192-0

27 Shalom AS. Blood loss in ear nose and throat operations. J Laryngol Otol 1964;78:734-756. Doi: 10.1017/S0022215100062691

28 Prasad KC, Prasad SC. Assessment of Operative Blood Loss and the Factors Affecting it in Tonsillectomy and Adenotonsillectomy. Indian J Otolaryngol Head Neck Surg 2011;63(04):343-348. Doi: $10.1007 / \mathrm{s} 12070-011-0268-9$ 